\title{
Carcinoma In Situ
}

National Cancer Institute

\section{Source}

National Cancer Institute. Carcinoma In Situ. NCI Thesaurus. Code C2917.

A malignant epithelial neoplasm which is confined to the epithelial layer without evidence

of further tissue invasion. 